\title{
PENGEMBANGAN TEKNOLOGI MOBILE UNTUK SISTEM KASIR RUMAH MAKAN DI KOTA SAMPIT MENGGUNAKAN FIREBASE REALTIME DATABASE
}

\author{
Kurniawati $^{1)}$, dan Lukman Bachtiar ${ }^{2)}$ \\ ${ }^{1,2)}$ Jurusan Sistem Informasi, Fakultas Ilmu Komputer, UNDA University \\ Jl. Batu Berlian No. 10, Sampit - Kalimantan Tengah \\ e-mail: kurniawati.vivo@gmail.com ${ }^{1)}$, lukman.bachtiar@gmail.com ${ }^{2)}$
}

\begin{abstract}
ABSTRAK
Trend masyarakat yang sedang berkembang sekarang yaitu mereka cenderung lebih tertarik terhadap teknologi yang dapat memberikan kemudahan, baik dalam penerapannya maupun penggunaannya. Salah satu contoh teknologi informasi yang diperlukan zaman sekarang adalah sistem kasir. Sistem kasir merupakan sebuah teknologi informasi yang dapat melakukan perhitungan total belanjaan secara cepat dan akurat serta bisa menampilkan laporan penjualan. Sistem ini biasanya diterapkan pada sebuah toko retail, rumah makan dan lainnya serta dapat diterapkan dalam basis desktop, web maupun mobile. Meskipun teknologi ini sudah lama ditemukan, namun faktanya masih banyak toko-toko atau rumah makan yang belum menerapkan teknologi ini dalam kegiatan bisnis mereka terutama di kota Sampit. Proses pembuatan aplikasi ini menggunakan bahasa pemrograman Java serta beberapa software pendukung yaitu Android Studio, BlueStack serta Firebase Console yang digunakan untuk pembuatan program, database dan user interface.
\end{abstract}

Kata Kunci: Android Studio, Mobile, Realtime Database, Sistem Kasir, Teknologi

\section{ABSTRACT}

The trend of society that is currently developing is that they tend to be more interested in technology that can provide convenience, both in its application and use. One example of the information technology needed today is the cashier system. The cashier system is an information technology that can calculate total purchases quickly and accurately and can display sales reports. This system is usually applied to a retail store, restaurant, and others and can be applied on a desktop, web or mobile basis. Although this technology has been invented for a long time, in fact, there are still many shops or restaurants that have not implemented this technology in their business activities, especially in the city of Sampit. Seeing this, the researchers proposed a cashier system to be applied to restaurants in the city of Sampit on a mobile basis. Today's mobile bases tend to be in demand and are easy to implement and use. The process of making this application uses the Java programming language and some supporting software, namely Android Studio, BlueStack, and Firebase Console, for creating programs, database, and user interfaces.

Keywords: Android Studio, Cashier System, Mobile, Realtime Database, Technology

\section{PEndahuluan}

$\mathrm{P}$ erkembangan zaman yang semakin pesat membuat manusia harus beradaptasi dengannya. Hal ini menimbulkan kebutuhan-kebutuhan baru yang harus bisa dipenuhi secara tepat dan cepat. Di era digital seperti sekarang, teknologi informasi dan manajemen dapat dikatakan sudah menjadi kebutuhan yang mendasar (primer). Trend masyarakat yang sedang berkembang sekarang yaitu mereka cenderung lebih tertarik terhadap teknologi yang dapat memberikan kemudahan, baik dalam penerapannya maupun penggunaannya.

Salah satu contoh teknologi informasi yang diperlukan zaman sekarang adalah sistem kasir. Sistem kasir merupakan sebuah teknologi informasi yang dapat melakukan perhitungan total belanjaan secara cepat dan akurat. Selain itu, sistem ini juga sudah berkembang sehingga bisa menampilkan laporan penjualan baik untuk laporan harian, mingguan maupun bulanan. Sistem ini biasanya diterapkan pada sebuah toko retail, rumah makan dan lainnya serta dapat diterapkan dalam basis desktop, web maupun mobile.

Meskipun teknologi ini sudah lama ditemukan, namun faktanya masih banyak toko-toko atau rumah makan yang belum menerapkan teknologi ini dalam kegiatan bisnis mereka terutama di kota Sampit. Berdasarkan observasi yang sudah penulis lakukan pada salah satu rumah makan di kota Sampit yaitu "Warung Ayam Panggang Martapura" di mana rumah makan ini merupakan tempat yang menjadi studi kasus saat melakukan penelitian, terdapat beberapa permasalahan yang sering dihadapi dalam kegiatan usaha jika dalam kegiatannya masih belum menerapkan sistem kasir. Beberapa permasalahan tersebut diantaranya sering terjadi kesalahan dalam perhitungan total transaksi, lambat dalam perhitungan transaksi, kesulitan dalam pembuatan laporan, terlalu banyak tumpukan dokumen penjualan dan permasalahan lainnya. 
Sistem kasir tentu saja dapat membantu semua permasalahan yang sudah disebutkan di atas, karena pada dasarnya sistem ini memang dibuat untuk mempermudah kegiatan usaha suatu toko retail ataupun rumah makan. Sistem kasir yang akan peneliti usulkan untuk diterapkan yaitu sistem yang berbasis mobile. Keuntungan sebuah sistem dalam basis mobile yaitu tidak perlu menyediakan ruang yang cukup luas, berbeda dengan penerapan sistem yang menggunakan satu set PC (basis web). Dari segi biaya juga tentu saja lebih murah karena perangkat yang diperlukan hanya satu buat smartphone atau tab dan satu buah printer bluetooth.

Pada penelitan terdahulu menyatakan bahwa peranan teknologi informasi sebagai alat bantu manusia untuk pengolahan data menjadikan informasi menjadi lebih mudah untuk didapatkan. Perkembangan aplikasi di bidang bisnis dan perdagangan juga dapat membantu pelaku bisnis untuk mengembangkan usaha mereka dengan baik [1] [2]. Berdasarkan beberapa hal sudah dipaparkan yang menjadi dasar bagi penulis untuk memutuskan melakukan penelitian dengan membuat sebuah sistem kasir yang dapat diterapkan pada warung makan sebagai solusi atas permasalahan yang sudah dijelaskan.

\section{METODOLOGI PENELITIAN}

Pada penelitian ini penulis menggunakan metode-metode sebagai berikut:

\section{A. Pengumpulan Data}

1) Studi Pustaka

Peneliti mengumpulkan data dengan cara mencari referensi buku tentang penelitian terdahulu yang masih berkaitan dengan penelitian yang dilakukan sekarang.

2) Observasi

Peneliti mengumpulkan data dengan cara mengamati secara langsung kegiatan usaha yang terjadi di rumah makan yang ada di kota Sampit. Mengamati bagaimana owner mengatur kinerja karyawan serta bagaimana tanggapan pelanggan terhadap sistem kerja yang mereka terapkan.

3) Wawancara

Mengumpulkan data dengan cara mewawancarai pemilik rumah makan di kota Sampit beserta karyawankaryawan yang bekerja di rumah makan tersebut.

\section{B. Pengembangan Sistem}

1) Analisis Data

Melakukan analisis terhadap data yang sudah dikumpulkan. Hal ini dilakukan dengan tujuan untuk memberikan jawaban atas permasalahan yang sedang diteliti. Proses didalamnya meliputi beberapa hal yaitu mengurutkan data serta mengorganisasikannya ke dalam suatu pola atau kategori.

2) Desain Sistem

Tahap ini merupakan kegiatan perancangan awal dari sistem baru yang akan dibuat. Pada tahapan ini desain sistem dapat memberikan gambaran tentang bagaimana sistem baru akan membantu dalam mengatasi masalah pada sistem lama.

3) Pembuatan Program

Peneliti membuat program berdasarkan data yang sudah dikumpulkan dan dianalisis sebelumnya. Pembuatan program juga dilakukan berdasarkan desain sistem yang sudah dibuat agar sesuai dengan tujuan awal pembuatan program. Data-data tersebut diterjemahkan ke dalam bahasa pemrograman tertentu sesuai dengan penelitian.

4) Pengujian

Merupakan tahap pengujian apliaksi yang sudah dibangun.

5) Implementasi

Tahap ini adalah tahapan di mana aplikasi yang sudah dibuat dan lolos uji coba sebelumnya akan diimplementasikan atau diterapkan sesuai dengan tujuan pembuatan sistem.

\section{LANDASAN TEORI}

\section{A. Definisi Mobile}

Pengertian mobile adalah perpindahan yang mudah dari satu tempat ke tempat yang lain, misalnya telepon mobile berarti bahwa terminal telepon yang dapat berpindah dengan mudah dari satu tempat ke tempat lain tanpa terjadi pemutusan atau terputusnya komunikasi. Sistem Aplikasi mobile merupakan aplikasi yang dapat digunakan walau- 
pun pengguna berpindah dengan mudah dari satu tempat ke tempat lain tanpa terjadi pemutusan atau terputusnya komunikasi. Aplikasi ini dapat diakses melalui perangkat nirkabel seperti pager, seperti telepon seluler dan PDA[3].

\section{B. Definisi Sistem}

Sistem merupakan suatu rangkaian yang terdiri dari dua atau lebih komponen yang saling berhubungan dan saling berinteraksi satu sama lain untuk mencapai tujuan dimana sistem biasanya terbagi dalam sub sistem yang lebih kecil yang mendukung sistem yang lebih besar[4].

Sistem juga dapat diartikan sebagai elemen-elemen yang saling berhubungan dan berinteraksi dalam satu kesatuan untuk menjalankan suatu proses pencapaian suatu tujuan utama[5]. Dengan kata lain sistem adalah kumpulan/group dari sub sistem/bagian/komponen apapun baik fisik ataupun non fisik yang saling berhubungan satu sama lain dan bekerja sama secara harmonis untuk mencapai satu tujuan tertentu[6].

\section{Definisi Kasir}

Dilansir dari website resmi KBBI, kasir adalah seorang pemegang kas (uang) atau orang yang bertugas menerima dan membayarkan uang. Selain istilah kasir, ada juga istilah kassa. Keduanya mempunyai perbedaan. Kasir adalah orangnya, sedangkan kassa adalah tempatnya.

\section{Firebase Realtime Database}

Firebase adalah BaaS (Backend as a Service) yang saat ini dimiliki oleh Google. Firebase sendiri merupakan solusi yang ditawarkan oleh Google untuk mempermudah pekerjaan Mobile Apps Developer. Dengan adanya Firebase, apps developer tentu saja dapat fokus mengembangkan aplikasi tanpa harus memberikan effort yang besar untuk urusan backend[3].

Firebase Realtime Database sendiri merupakan basis data berbasis cloud NoSQL yang menyinkronkan data di semua klien secara realtime, dan menyediakan fungsionalitas offline. Data yang diinputkan disimpan ke dalam database Realtime sebagai JSON. Semua klien yang terhubung dan saling berbagi dalam satu waktu, secara otomatis akan menerima pembaruan dengan data terbaru[7].

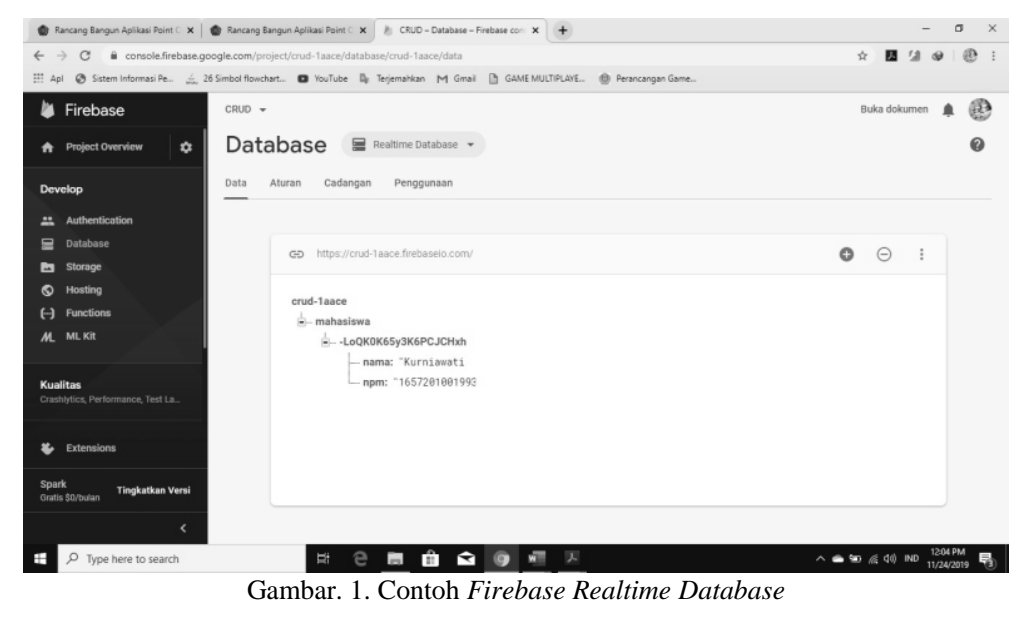

Database ini sendiri merupakan database yang disediakan oleh Google dan memiliki 2 solusi database dalam pengunaannya, Solusi pertama disebut Cloud Firetstore. Cloud Firestore adalah database terbaru dari Firebase untuk pengembangan aplikasi seluler. Database ini melanjutkan keberhasilan Realtime Database dengan model data baru yang lebih intuitif.

\section{E. Bahasa Java}

Java menurut definisi dari Sun adalah nama untuk sekumpulan teknologi untuk membuat dan menjalankan perangkat lunak pada komputer standalone ataupun pada lingkungan jaringan. Java dikembangkan pada bulan Agustus 1991, dengan nama semula Oak. Pada Januari 1995, karena nama Oak dianggap kurang komersial, maka diganti menjadi Java. Pada Desember 1998, Sun memperkenalka nama "Java 2" (J2) sebagai generasi kedua dari java platform. Konvensi nama baru ini diterapkan untuk semua edisi Java yaitu Standard Edition (J2SE), Enterprise Edition (J2EE), dan Micro Edition (J2ME)[8]. 


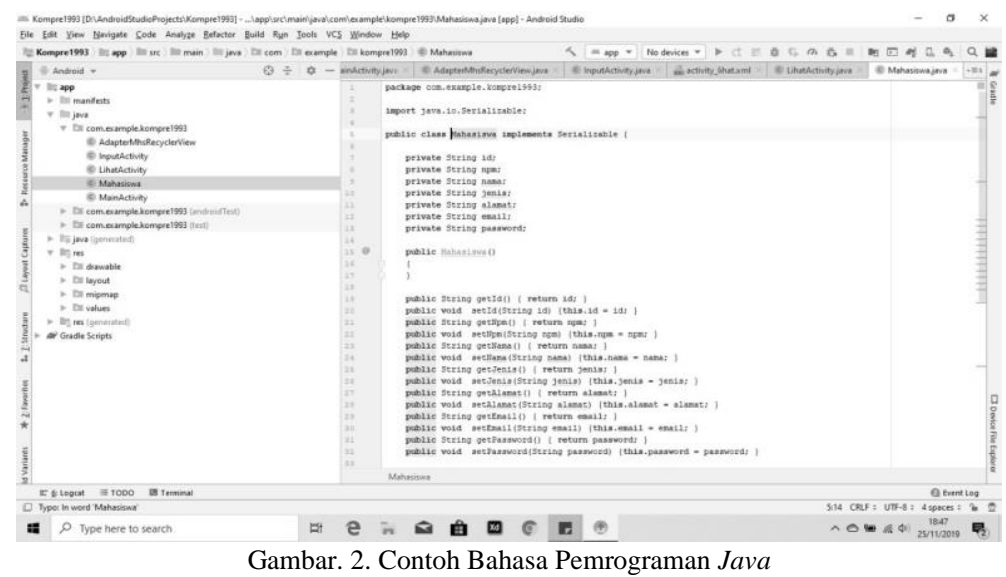

Java dirancang untuk mudah dipelajari, terutama bagi programmer yang telah mengenal C/C++ akan mudah sekali untuk berpindah ke Java. Bahasa pemrograman ini bukan turunan langsung dari bahasa pemrograman manapun[8].

\section{F. Android Studio}

Android studio adalah IDE (Integrated Development Environment) resmi untuk pengembangan aplikasi Android dan bersifat open source atau gratis. Peluncuran Android Studio ini diumumkan oleh Google pada 16 mei 2013 pada event Google I/O Conference untuk tahun 2013. Sejak saat itu, Android Studio mengantikan Eclipse sebagai $I D E$ resmi untuk mengembangkan aplikasi Android[9].

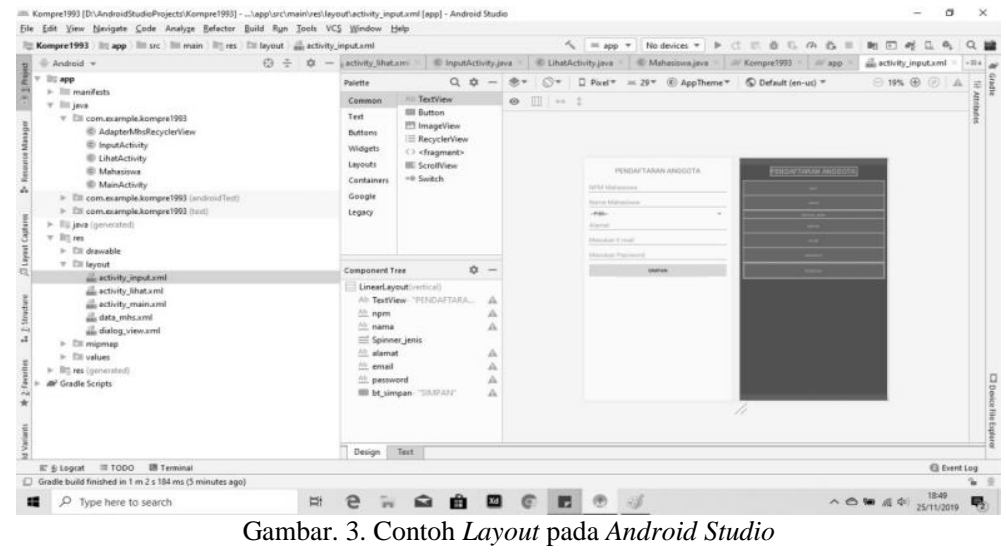

\section{HASIL DAN PEMBAHASAN}

\section{A. Implementasi Sistem}

Tahap implementasi merupakan tahap akhir dari proses membangun sebuah sistem. Pada tahap ini seluruh rancangan yang sudah dihasilkan, diterjemahkan dengan mengunakan bahasa pemrograman sehingga menghasilkan sebuah sistem yang diinginkan. Dalam implementasi sistem kasir pada rumah makan di Sampit menggunakan firebase realtime database berbasis mobile dilakukan dengan meng-install file .apk yang ada ke smartphone Vivo Y69. Pengujian dilakukan dengan menggunakan smartphone dengan sistem operasi Android. Proses pertama saat program ini dijalankan akan tampil halaman utama di mana pada halaman ini akan ada dua buah button, satu untuk daftar dan satu untuk masuk seperti pada gambar di bawah ini: 


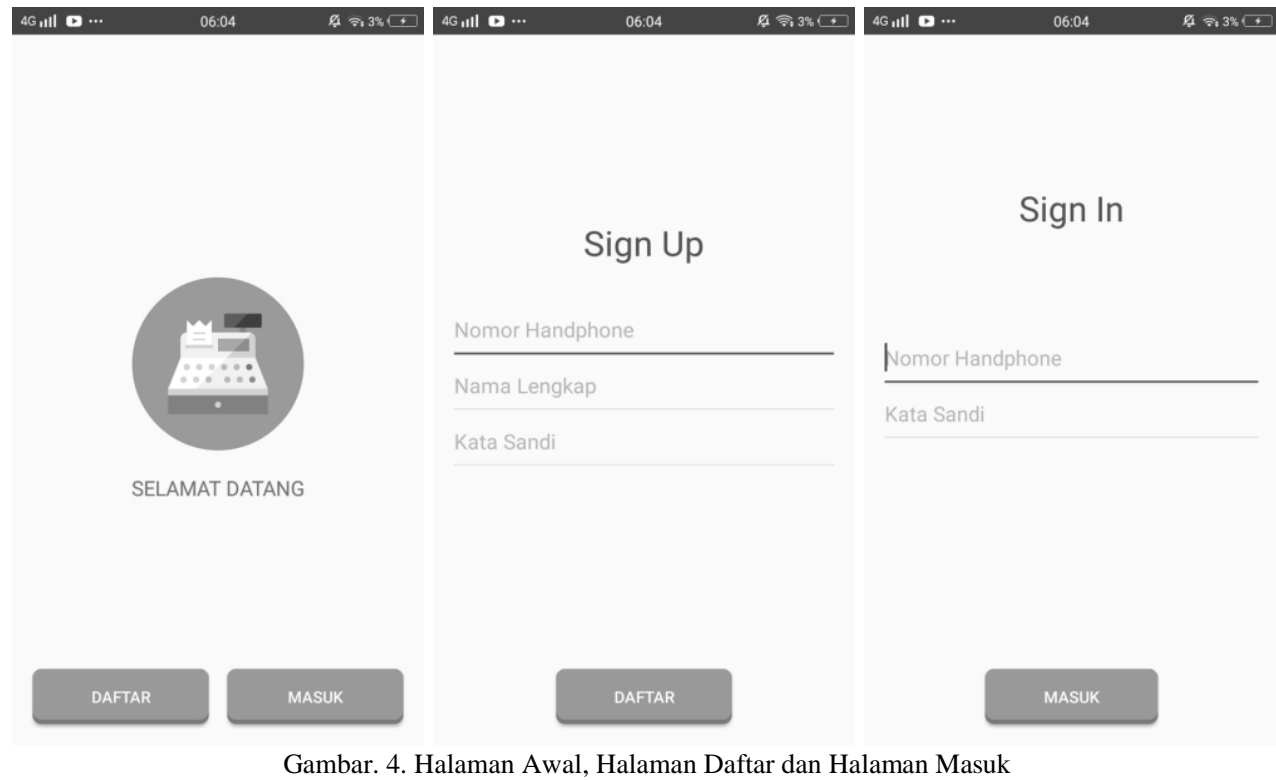

Gambar. 4. merupakan tampilan awal saat pengguna membuka aplikasi sistem kasir. Pada halaman ini akan menampilkan dua tombol, satu tombol yaitu untuk daftar jika pengguna belum memiliki akun, sedangkan tombol lainnya untuk masuk ke sistem. Tombol daftar akan membawa pengguna menuju halaman daftar dan tombol masuk akan membawa pengguna menuju halaman masuk.

Pada halaman daftar pengguna harus mendaftar atau membuat akun terlebih dahulu agar dapat masuk ke sistem. Halaman ini mengharuskan pengguna mengisi data berupa nomor handphone, nama lengkap serta kata sandi. Jika sudah diisi dengan benar, pengguna tinggal meng-klik tombol daftar dan sistem akan melakukan pengecekan data. Jika data pengguna (nomor handphone) belum terdaftar maka akun akan berhasil dibuat. Jika sudah terdaftar maka sistem akan memberikan peringatan berupa "pengguna sudah terdaftar".

Sementara itu pada halaman masuk pengguna harus mengisikan data berupa nomor handphone dan kata sandi yang sudah didaftarkan sebelumnya terlebih dahulu agar dapat masuk ke sistem. Sistem akan melakukan pengecekan data terlebih dahulu, apakah data yang dimasukkan sudah sesuai dengan data yang ada di database atau belum. Jika sudah sesuai maka sistem akan membawa pengguna masuk ke dalam sistem yaitu menuju ke halaman daftar menu. Jika belum sesuai maka sistem akan menampilkan peringatan berupa "kata sandi salah" atau "pengguna belum terdaftar".

\section{1) Halaman Utama}

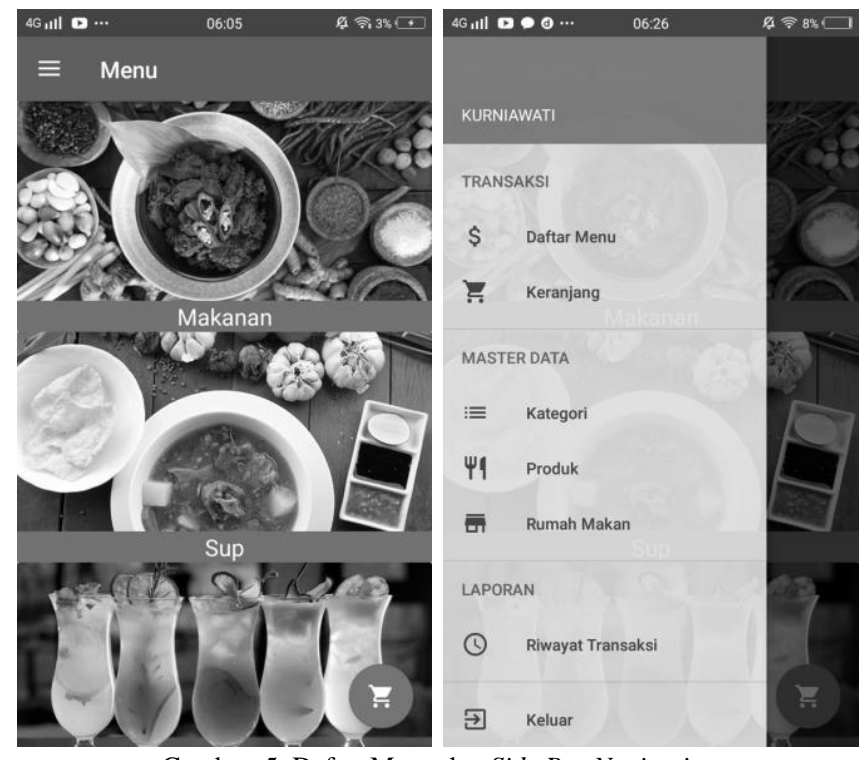

Gambar. 5. Daftar Menu dan Side Bar Navigation 
Gambar. 5. merupakan halaman daftar menu dan bar navigasi sistem. Halaman ini akan menampilkan daftar menu yang dibagi berdasarkan kategori. Pada halaman ini juga terdapat satu buah side bar navigation serta satu buah float button untuk menuju ke halaman keranjang. Terdapat beberapa pilihan pada side bar ini dimana seluruhnya (berupa master data, transaksi dan laporan) dijadikan satu tempat agar mempermudah pengguna dalam meng-akses halaman-halaman yang diinginkan. Pada side bar ini juga terdapat satu pilihan untuk keluar serta pada pojok kiri atas (tepatnya di atas tulisan daftar menu) terdapat teks untuk menampilkan nama pengguna yang sedang masuk ke sistem.

2) Halaman Master Data

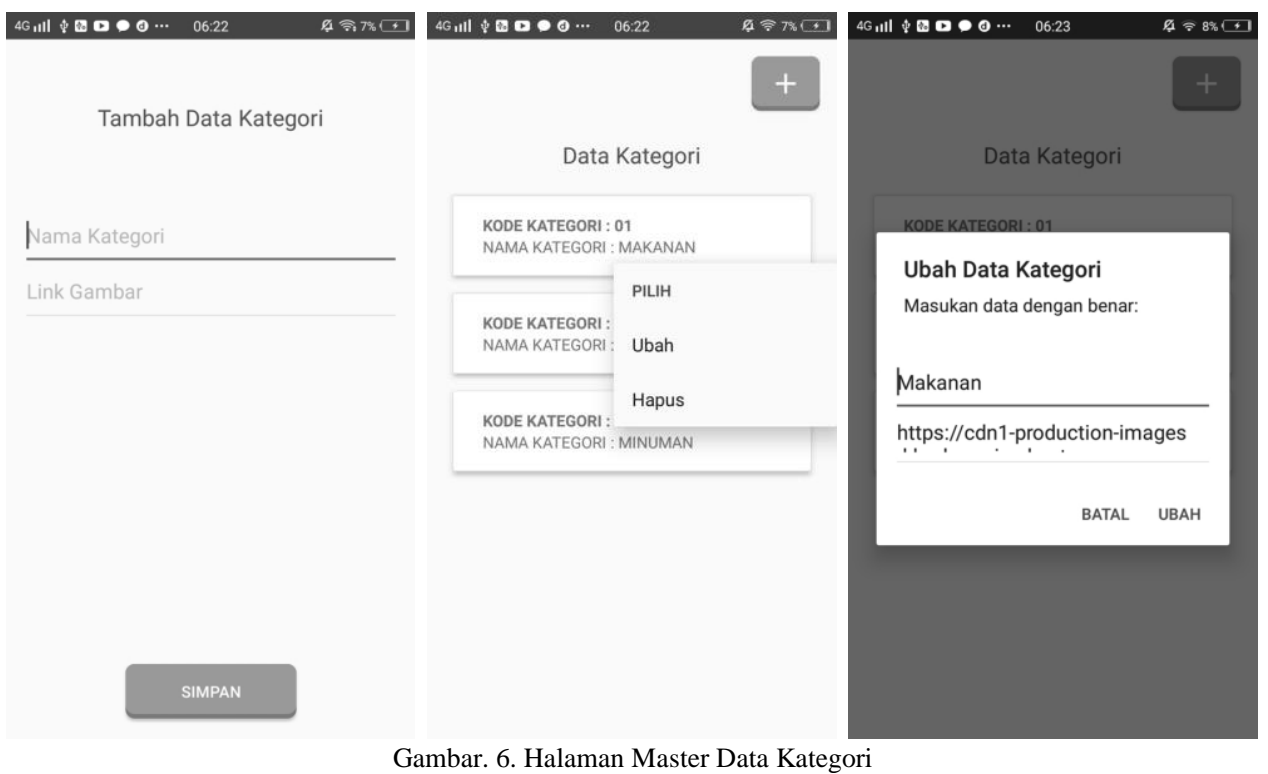

Gambar. 6. merupakan halaman untuk mengelola data kategori. Pada halaman ini pengguna dapat dengan mudah membuat data kategori berdasarkan rumah makan masing - masing atau sesuai keinginan. Pada halaman ini pengguna juga dapat melihat daftar kategori yang sudah dibuat dan disimpan ke dalam database. Jika salah satu data di-klik selama beberapa detik, akan muncul рор up pilihan untuk mengubah data atau menghapus data. Data yang ditampilkan untuk diubah secara otomatis mengambil data dari item yang dipilih oleh pengguna pada halaman sebelumnya.

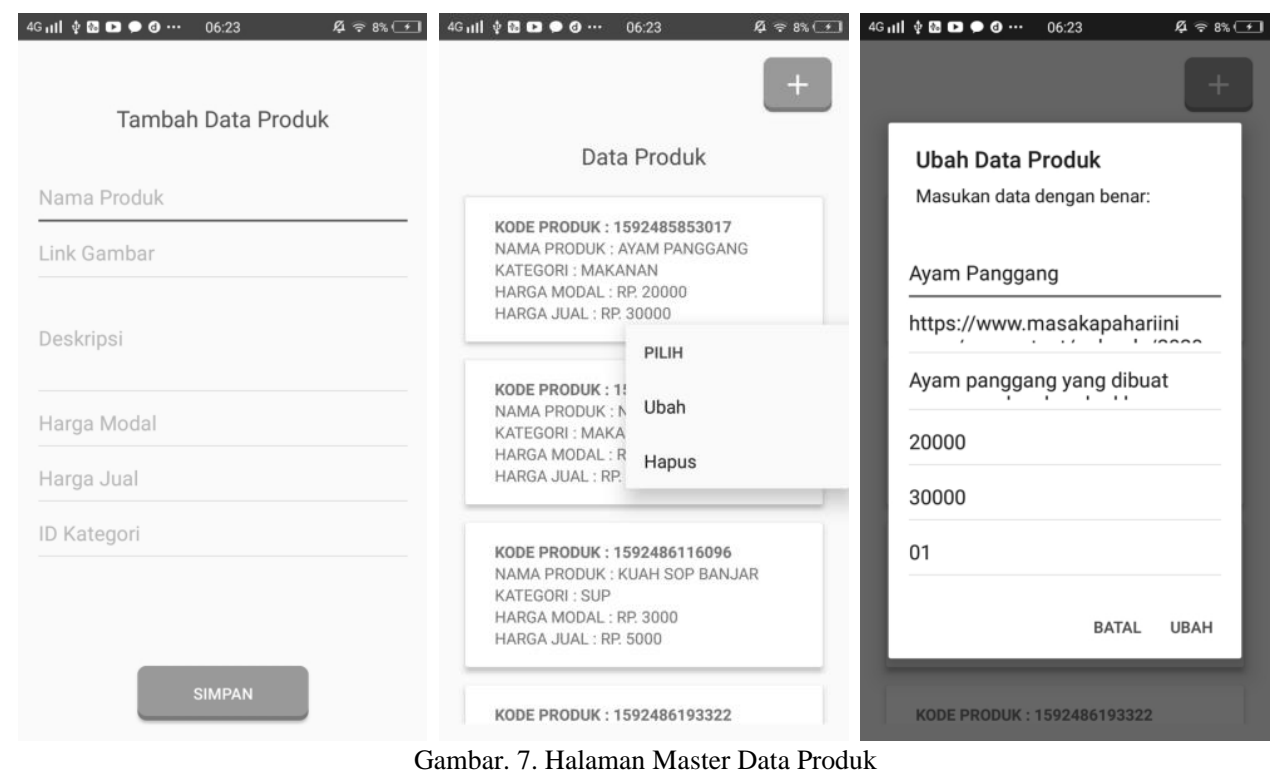

Gambar. 7. merupakan halaman untuk mengelola data produk. Pengguna dapat menambahkan data produk dengan cara meng-klik tombol tambah di pojok kanan atas. Data produk dapat diisi sesuai dengan menu rumah makan mereka masing-masing. Halaman ini juga dapat menampilkan daftar produk yang sudah pengguna simpan pada halaman sebelumnya. Pada halaman ini juga terdapat pop up pilihan untuk mengubah data atau menghapus 
data produk jika pengguna menekan salah satu item selama beberapa detik. Data yang ditampilkan untuk diubah merupakan data produk yang diambil secara otomatis berdasarkan item yang dipilih pengguna pada halaman sebelumnya.

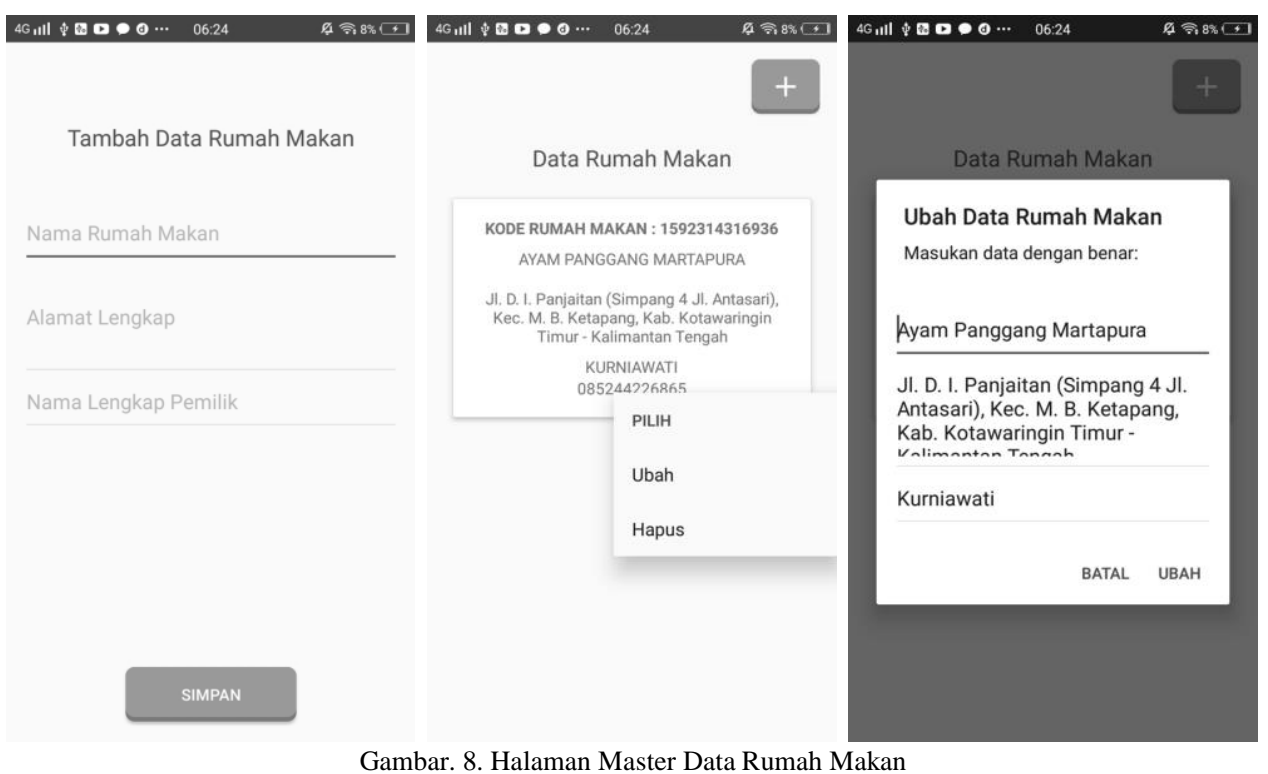

Gambar. 8. merupakan halaman untuk mengelola data rumah makan. Pada halaman ini pengguna dapat dengan mudah menambahkan data rumah makan berdasarkan data rumah makan masing-masing. Halaman juga dapat menampilkan data rumah makan yang sudah disimpan pada halaman sebelumnya. Sama seperti halaman lainnya, halaman ini juga akan menampilkan pop up pilihan ubah data atau hapus data rumah makan jika pengguna menekan selama beberapa detik pada salah satu item yang dipilih. Data yang akan diubah juga ditampilkan secara otomatis berdasarkan item yang dipilih pengguna pada halaman sebelumnya.

\section{3) Halaman Transaksi}
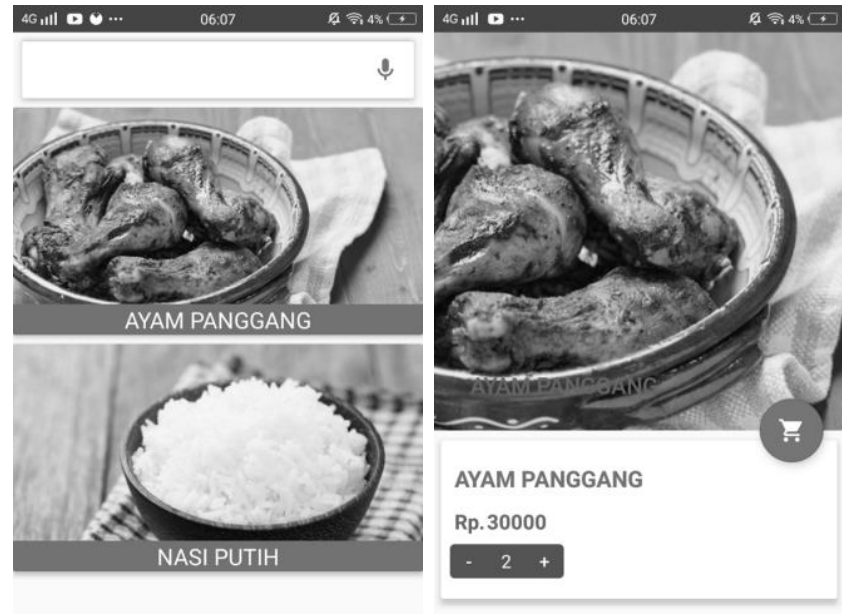

Ayam Panggang yang dibuat menggunakan bumbu khusus khas Rumah Makan Ayam Panggang Martapura
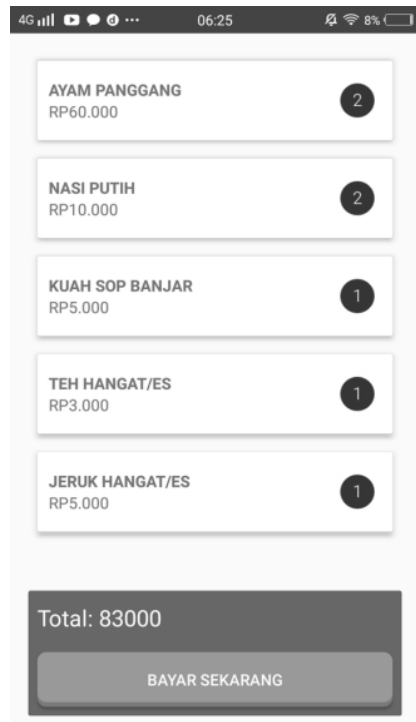

\section{BAYAR SEKARANG}

Gambar. 9. Halaman Transaksi

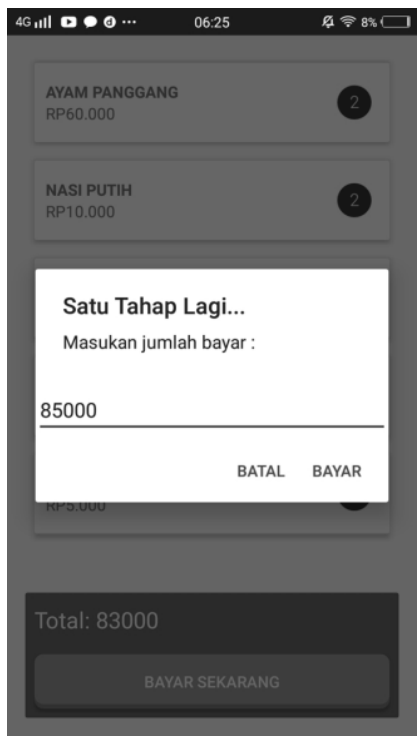

Gambar. 9. merupakan halaman saat pengguna memilih salah satu kategori yang sudah ada pada halaman sebelumnya. Setelah memilih data kategori, pengguna akan dibawa pada halaman daftar menu dimana menu yang ditampilkan adalah menu yang sesuai dengan kategori dari menu itu sendiri. 
Jika salah satu menu dipilih, maka sistem akan menampilkan detail dari menu yang sudah dipilih pada halaman sebelumnya. Pada halaman ini pengguna akan disuguhkan informasi berupa nama produk, harga produk serta gambar dan deskripsi produk. Pada halaman ini penguna juga bisa memasukan beberapa data seperti jumlah porsi dan memasukan data pesanan ke keranjang.

Pada halaman keranjang, pengguna akan disuguhkan informasi produk apa saja yang dipesan serta harga dari masing-masing produk. Pengguna juga akan disuguhkan informasi total pesanan. Jika pesanan sudah sesuai, pengguna tinggal meng-klik tombil bayar sekarang untuk memproses transaksi.

Jika pengguna sudah meng-klik tombol bayar sekarang, akan muncul pop up di mana pengguna diharuskan memasukan jumlah yang dibayarkan oleh pelangan mereka saat pelanggan tersebut akan membayarkan total tagihan. Jika sudah sesuai, pengguna meng-klik tombol bayar dan transaksi akan diproses serta data transaksi akan tersimpan ke dalam database.

\section{4) Halaman Laporan}

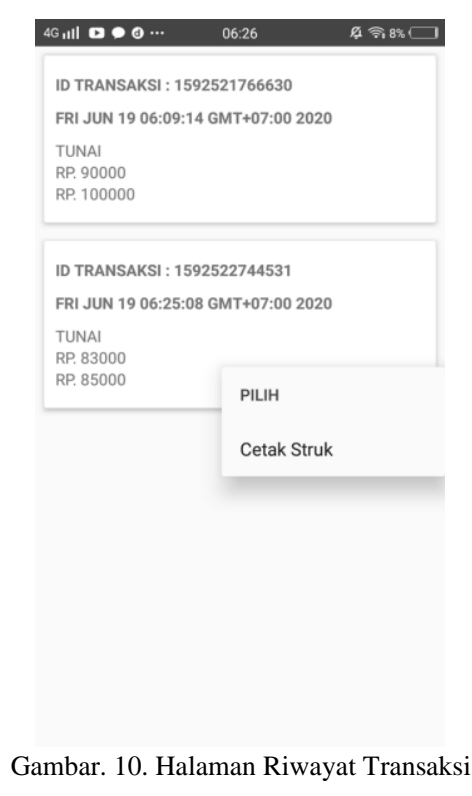

Gambar. 10. merupakan halaman untuk menampilkan daftar riwayat transaksi yang sudah dilakukan sebelumnya. Halaman ini akan menampilkan informasi berupa ID Transaksi, Tanggal Transaksi, Metode Pembayaran, Total Pesanan serta Total Bayar. Jika pengguna meng-klik salah satu item selama beberapa detik, sistem akan menampilkan рор up pilihan untuk mencetak struk/nota tagihan.

\section{B. Pengujian Sistem}

Pengujian sistem dilakukan untuk melihat apakah aplikasi yang sudah dibuat telah berjalan sesuai dengan yang diharapkan atau masih ada kesalahan yang terjadi sehingga aplikasi masih harus diperbaiki. Aplikasi yang dibuat sudah diimplementasikan pada salah satu rumah makan yang menjadi tempat studi kasus peneliti dalam melakukan penelitian.

Di bawah ini akan dilakukan pengujian untuk input dan output sistem. Pengujian pada aplikasi sistem kasir berbasis mobile dapat dilihat pada tabel di bawah ini:

Tabel 1. Hasil Pengujian Terhadap Master Data

\begin{tabular}{|c|c|c|c|c|}
\hline \multicolumn{5}{|c|}{ MASTER DATA } \\
\hline No & Masukan & Keluaran & Hasil & Kesimpulan \\
\hline 1 & $\begin{array}{l}\text { Data diisi dengan } \\
\text { lengkap dan benar }\end{array}$ & Input Berhasil & Data Tersimpan ke Database & Valid \\
\hline 2 & $\begin{array}{l}\text { Data diisi dengan } \\
\text { data yang salah }\end{array}$ & Input Gagal & Data tidak tersimpan ke Database & Valid \\
\hline 3 & $\begin{array}{l}\text { Data tidak diisi } \\
\text { sama sekali }\end{array}$ & Input Gagal & Data tidak tersimpan ke Database & Valid \\
\hline 4 & Data dihapus & Hapus Data Berhasil & Data terhapus dari Database & Valid \\
\hline
\end{tabular}

Pada tabel 1. dapat dilihat bahwa pengujian untuk proses CRUD (Create, Read, Update dan Delete) atau pengelolaan pada master data baik untuk master data pengguna, kategori, produk maupun rumah makan dapat dilakukan dengan baik dan benar dengan menggunakan sistem kasir berbasis mobile. 
Tabel 2. Hasil Pengujian Terhadap Transaksi

\section{TRANSAKSI}

\begin{tabular}{|l|l|l|l|l|}
\hline No & Masukan & Keluaran & Hasil & Kesimpulan \\
\hline $\mathbf{1}$ & $\begin{array}{l}\text { Sistem menampilkan } \\
\text { daftar menu berdasar- } \\
\text { kan master data } \\
\text { produk dan kategori }\end{array}$ & $\begin{array}{l}\text { Daftar Menu Rumah } \\
\text { Makan }\end{array}$ & $\begin{array}{l}\text { Data berhasil ditampilkan dari Data- } \\
\text { base }\end{array}$ & Valid \\
\hline $\mathbf{2}$ & $\begin{array}{l}\text { Data pesanan diisi } \\
\text { dengan lengkap dan } \\
\text { benar Input Berhasil }\end{array}$ & Data tersimpan ke Database & Valid \\
\hline $\mathbf{3}$ & $\begin{array}{l}\text { Sistem melakukan } \\
\text { perhitungan secara } \\
\text { cepat dan akurat }\end{array}$ & Input Berhasil & Data tersimpan ke Database & Valid \\
\hline
\end{tabular}

Pada tabel 2. dapat dilihat bahwa pengujian untuk proses transaksi dapat dilakukan dengan baik dan benar dengan menggunakan sistem kasir berbasis mobile. Proses transaksi dimulai dari sistem yang menampilkan daftar menu berdasarkan master data yang sudah tersimpan di database, kemudian kasir memilih daftar menu berdasarkan pesanan pelanggan. Setelah daftar pesanan sudah dipilih, kasir kemudian melakukan proses input transaksi di mana proses perhitungan langsung dilakukan oleh sistem kasir secara cepat dan akurat. Hal ini tentu saja dapat mengurangi kesalahan seorang kasir yang umum terjadi seperti kesalahan dalam perhitungan transaksi maupun lambat dalam perhitungan total transaksi.

Tabel 3. Hasil Pengujian Terhadap Laporan

\begin{tabular}{|c|c|c|c|c|}
\hline \multicolumn{5}{|c|}{ LAPORAN } \\
\hline No & Masukan & Keluaran & Hasil & Kesimpulan \\
\hline 1 & $\begin{array}{lr}\text { Sistem } & \text { menampilkan } \\
\text { daftar } & \text { riwayat } \\
\text { transaksi } & \end{array}$ & $\begin{array}{l}\text { Daftar } \quad \text { Riwayat } \\
\text { transaksi }\end{array}$ & $\begin{array}{l}\text { Data berhasil ditampilkan dari Data- } \\
\text { base }\end{array}$ & Valid \\
\hline 2 & $\begin{array}{l}\text { Sistem menampilkan } \\
\text { detail transaksi }\end{array}$ & Detail transaksi & $\begin{array}{l}\text { Data berhasil ditampilkan dari Data- } \\
\text { base }\end{array}$ & Valid \\
\hline 3 & $\begin{array}{l}\text { Sistem menampilkan } \\
\text { laporan penjualan }\end{array}$ & Null & Data gagal ditampilkan dari Database & Not Valid \\
\hline 4 & $\begin{array}{l}\text { Sistem dapat mence- } \\
\text { tak struk tagihan }\end{array}$ & Null & Sistem gagal mencetak struk tagihan & Not Valid \\
\hline
\end{tabular}

Pada tabel 3. dapat dilihat bahwa dari 4 jenis penyajian laporan, hanya 2 jenis laporan yang dapat disajikan oleh sistem yaitu laporan daftar riwayat transaksi dan detail transaksi. Sedangkan untuk laporan penjualan serta cetak struk tagihan sistem ini masih belum dapat melakukannya secara baik dan benar.

\section{KESIMPULAN}

Berdasarkan program yang sudah dibuat, diimplementasikan serta dilakukan pengujian sistem, kesimpulan yang dapat diambil dari pembuatan sistem kasir berbasis mobile menggunakan firebase realtime database adalah sebagai berikut:

A. Aplikasi dapat mengatasi pengelolaan master data yang diperlukan oleh pengguna (pemilik rumah makan) secara menyeluruh, baik itu master data pengguna, kategori, produk maupun rumah makan.

B. Aplikasi dapat membantu pengguna (pemilik rumah makan atau kasir) dalam hal proses transaksi yaitu pengguna dapat dengan mudah dan cepat dalam melakukan proses perhitungan total pesanan pelanggan sehingga dapat mengurangi resiko kesalahan dalam perhitungan, lambat dalam perhitungan, mengurangi pengguna kertas nota karena proses pencatatan dilakukan oleh sistem. Hal ini tentu saja juga berdampak pada efisiensi keuangan pemilik rumah makan karena penggunaan kertas nota menjadi berkurang.

C. Aplikasi dapat membantu pengguna dalam pencatatan laporan transaksi serta dapat menyajikan laporan riwayat transaksi dan detail transaksi. Hanya saja untuk aplikasi ini belum bisa menyajikan laporan penjualan serta belum bisa melakukan cetak struk tagihan. 


\section{DAFTAR PUSTAKA}

[1] D. Faturohman, P. Eosina, and F. Riana, "PERANCANGAN APLIKASI KASIR BERBASIS ANDROID (STUDI KASUS TOKO USAHA TANI LEUWILIANG)," in Seminar Nasional Teknologi Informasi, 2018, vol. 1.

[2] G. Pamungkas and H. Yuliansyah, "Rancang Bangun Aplikasi Android Pos (Point of Sale) Kafe Untuk Kasir Portable dan Bluetooth Printer," JST J. Sains Dan Teknol., vol. 6, no. 1, 2017.

[3] A. N. Ananda, "Mobile Commerce Berbasis Android Pada PT. Mega Mulia Pharma Palembang," PhD Thesis, POLITEKNIK NEGERI SRIWIJAYA, 2018.

[4] F. O. Voets, "Analisis Sistem Informasi Akuntansi Siklus Penjualan dan Penerimaan Kas untuk Meningkatkan Pengendalian Intern Pada PT. Sumber Alfaria Trijaya, Tbk (Alfamart) cabang Manado," J. Berk. Ilm. Efisiensi, vol. 16, no. 4, 2016.

[5] D. Saputra, A. H. Masud, M. Ramdhan, and D. Fitriani, “Akses Kontrol Ruangan Menggunakan Sensor Sidik Jari Berbasis Mikrokontroler ATMEGA328P," STMIK Raharja, 2014.

[6] A. Susanto, "Sistem Informasi Akuntansi," Bdg. Lingga Jaya, 2013.

[7] L. Moroney, "The firebase realtime database," in The Definitive Guide to Firebase, Springer, 2017, pp. 51-71.

[8] M. Tasmawati, "APLIKASI KONVERSI REGULAR GRAMMAR MENJADI EKSPRESI REGULAR DENGAN MENGGUNAKAN BAHASAPEMROGRAMAN JAVA,” Skripsi Program Studi Tek. Inform., 2008.

[9] A. Juansyah, "Pembangunan Aplikasi Child Tracker Berbasis Assisted-Global Positioning System (A-Gps) Dengan Platform Android," J. Ilm. Komput. Dan Inform. KOMPUTA, vol. 1, no. 1, 2015. 